\title{
A REFERENCIAÇÃO COMO MARCA DISCURSIVO- ARGUMENTATIVA NA PRÁTICA JORNALÍSTICA INSTITUCIONAL
}

\section{REFERENCING AS A DISCURSIVE-ARGUMENTATIVE MARK IN INSTITUTIONAL JOURNALISTIC PRACTICE}

\author{
Josemar dos Santos" \\ Onici Claro Flôres ${ }^{* * *}$
}

Resumo: O presente artigo propõe-se a analisar os processos de referenciação inseridos nas marcas textuais discursivo-argumentativas utilizadas na prática jornalística institucional. Entende-se que, uma vez estabelecida a referenciação, esta se revela uma atividade discursiva na qual os objetos do discurso se (re)constroem e se transformam de acordo com a maneira como interagem com o mundo social do entorno acadêmico. O trabalho consiste em uma análise de duas notícias publicadas no portal de uma Instituição de Ensino Superior (IES) do Rio Grande do Sul. O objetivo principal é identificar e descrever de que forma é empregado o referido mecanismo nesse gênero jornalístico e como é realizada a referenciação ao longo da construção textual.

Palavras-chave: Prática jornalística institucional; Referenciação; Discurso.

ABstract: The present article aims to analyze the processes of referencing inserted in discursive-argumentative textual marks used in institutional journalistic practice. It is understood that, once established, referencing reveals itself as an activity in which the objects of discourse are both (re)constructed and transformed according to the way they interact with the academic world. This work consists of an analysis of two news articles published in the portal of a Higher Education Institution (IES) of Rio Grande do Sul. The primary objective is to identify and describe in what way the referred mechanism is employed in this journalistic genre and how the referencing is conducted along the textual construction.

KEYworDs: Institutional journalistic practice; Referencing; Speech.

\footnotetext{
"Doutorando do Programa de Pós-Graduação em Letras da Universidade de Santa Cruz do Sul (UNISC).

E-mail: josemarsantacruz@yahoo.com.br.

"* Professora do Programa de Pós-Graduação em Letras da Universidade de Santa Cruz do Sul (UNISC).

E-mail:onicifloresı@gmail.com.
} 


\section{INTRODUÇÃo}

O presente estudo enfoca os processos de referenciação utilizados como estratégias textuais e linguístico-discursivas em textos constantes no portal de notícias de uma Instituição de Ensino Superior (IES) do Rio Grande do Sul (RS). Objetiva-se identificar as estratégias textuais empregadas, avaliando-as em termos de recursos argumentativos, a fim de consolidar a imagem da instituição, ao propagar atividades acadêmicas, difundindo ações diversas e, ao mesmo tempo, atraindo novos alunos. Em especial, pretende-se analisar como a referenciação, atividade discursiva presente no sistema de interação verbal, possibilita usar distintas unidades linguísticas, enquanto escolhas significativas para construir o conteúdo que o produtor textual/ jornalista pretende divulgar. Importante ressaltar que as estratégias discursivas adotadas por assessorias de comunicação institucional nem sempre atendem todos os parâmetros jornalísticos exigidos, tais como a pluralidade e o direito ao contraditório, por exemplo, configurando-se em um lugar de produção que emula práticas e processos discursivos relativos ao jornalismo com o objetivo de se revestir de sentido de verdade, sem, contudo, estar comprometido com os padrões ético-jornalísticos. Tal processo acaba por (re)construir a realidade a partir da interação sociocultural propiciada pelo portal, que configura o objeto de discurso ao modo do enunciador, sem confundir-se com a realidade extralinguística ( $\mathrm{KOCH}, 2002)$.

Em vista desse manejo calculado, todo o discurso edifica uma representação que age como memória compartilhada, na qual, pelo menos em parte, os sucessivos estágios representativos são os responsáveis pelas seleções feitas pelos interlocutores, particularmente em se tratando de expressões referenciais (APOTHÉLOZ, 2003). A partir dessa construção, os discursos e as informações explícitas e implícitas são agregados à memória discursiva e, posteriormente, por meio de processos anafóricos, concretiza-se a retomada informacional sobre a qual intervêm saberes linguísticos construídos pelo próprio texto e conhecimentos inferíveis, de acordo com os conhecimentos prévios do leitor (KOCH, 2004).

Processualmente, a constituição da memória discursiva envolve estratégias de referenciação como construção ou ativação, quando um referente novo é introduzido; reconstrução ou reativação, quando um referente já presente na memória discursiva é reintroduzido; e desfocalização ou desativação, quando um novo referente é utilizado, passando a ocupar o lugar do foco anterior, sem, entretanto, extinguir o antigo, que pode ser retomado. Tais estratégias são mobilizadas usualmente, de forma a possibilitar diferentes efeitos de sentido no interlocutor (KOCH, 2002).

De acordo com Bakhtin (2003), todas as esferas da atividade humana relacionam-se à utilização da língua, ou seja, à produção de enunciados, sendo essa a forma mais importante de estabelecer interações entre os indivíduos humanos. Em alguns casos, os enunciados produzidos já trazem uma configuração composicional historicamente elaborada, sendo tais configurações denominadas gêneros do discurso. Por sua vez, o enunciado, propriamente dito, 
consiste em uma unidade real do discurso, podendo ser falado ou escrito, constituindo-se, pois, em um ato de comunicação social.

Com base nessas considerações preliminares, a análise proposta na elaboração deste artigo compreende duas reportagens de divulgação acadêmica publicadas no Portal de notícias de uma IES do RS, ambas veiculadas em 2019. Quanto ao emprego da referenciação como mecanismo discursivo presente na prática jornalística institucional, a análise textual fundamentou-se em pressupostos teóricos sobre referenciação, ancorando-se em Koch (2002, 2004), que salienta que, na interação, o sujeito opera o material linguístico que tem à sua disposição para representar estados de coisas, com vistas à concretização do seu projeto de dizer.

\section{A INTERAÇÃo ESTABELECIDA ENTRE LEITOR, AUTOR E TEXTO}

Tendo como foco de análise os processos de referenciação inseridos na prática jornalística institucional, enquanto recursos e elementos textuais discursivo-argumentativos, ao se falar em leitura, remete-se a Koch e Elias (2006). Essas autoras consideram que, para leitores ativos, a interação interativa entre leitor, autor e texto sempre se inicia a partir de antecipações e hipóteses do leitor. Dessa forma, a leitura é vista como uma atividade estratégica de levantamento de hipóteses, que se processa de acordo com objetivos específicos, associando o conhecimento do código linguístico a outros conhecimentos prévios existentes na memória do leitor.

Marcuschi (2008) ressalta que a leitura somente tem sentido quando o leitor consegue interligar os elementos aparentemente soltos no texto, vinculando-os ao conteúdo textual e contextual. Assim, como salientam Koch e Elias (2006), o leitor precisa associar informações, levantar hipóteses e produzir inferências, uma vez que "[...] a leitura e a produção de sentidos são atividades orientadas por nossa bagagem sociocognitiva: conhecimentos da língua e das coisas do mundo" (KOCH; ELIAS, 2006, p. 21).

Por outro lado, ao longo da leitura, ressalta Kleiman (1992), o indivíduo evoca conhecimentos anteriores, sejam linguísticos, textuais, enciclopédicos, intertextuais, sejam contextuais, os quais colaboram para a construção de sentidos do texto, apresentando cada qual características determinadas. O conhecimento textual se refere à percepção de como se organizam/estruturam os textos. Por exemplo, ao identificar, numa receita, a lista de ingredientes e o modo de preparo de uma torta, percebe-se o objetivo desse gênero textual (ensinar a fazer a torta). O conhecimento linguístico, de sua parte, associa-se às experiências linguístico-discursivas anteriores, como aquelas referentes a noções sobre construção de frases, valores semânticos e estrutura e distribuição textual. O conhecimento enciclopédico (também chamado conhecimento de mundo) remete a tudo o que é assimilado pelo leitor no decorrer de sua vida. O conhecimento intertextual colabora para a identificação das referênciaos, explícitas ou implícitas, a outros textos. Já o conhecimento contextual consiste na associação do texto a ser lido com o contexto de 
leitura e de produção do texto em leitura, o que significa dizer que contextualizar representa, também, perceber intencionalidades interacionais (SANTOS; CUBA RICHE; TEIXEIRA, 2012).

Com base no exposto, Koch e Elias (2006) esclarecem que o acionamento desses conhecimentos prévios, que, teoricamente, são separados apenas por questões didáticas, é essencial para a construção dos sentidos, o que inclui a reelaboração de referentes. Por isso, as referidas autoras enfatizam que construir a coerência de um enunciado depende sempre de os interlocutores partilharem conhecimentos, pois a coerência não está no texto, mas, sim, em um efetivo processo de interação entre falante/ouvinte ou autor/leitor.

Dessa forma, construir o sentido de um texto implica engendrar múltiplos processos referenciais. Segundo Cavalcante e Santos (2012), em todo texto, o enunciador constrói a referência com base numa interpretação do mundo real, recategorizando a informação precedente ao acrescentar novas predicações disponíveis. Por meio desse aporte de informação nova, o enunciador conduz o destinatário que coparticipa da construção discursiva, sendo, por isso, um coenunciador da reinterpretação do elemento referido. Ou seja, pelas estratégias de recategorização, a ideia do referente que o coenunciador constrói em sua memória evolui à medida que se desenvolve o processo discursivo presente no texto em leitura.

\section{DO CONCEITO DE REFERÊNCIA AO CONCEITO DE REFERENCIAÇÃO}

Em termos de estudos linguísticos, é importante aqui ressaltar que a relação estabelecida entre a língua, o mundo e a significação tem sido objeto de bastante interesse. O principal objetivo desse tipo de pesquisa consiste em averiguar de que forma a língua representa ou se refere às "coisas" do mundo. Desse ponto de vista, surgiram duas perspectivas que remetem a conceitos distintos: a noção de referência tal qual é proposta por estudiosos racionalistas, e a teorização que vem se opondo a essa corrente, a qual emprega o conceito de referenciação, tendo sido introduzida por Apothéloz (2003); Mondada e Dubois (2003); Koch (2002); e Koch e Marcuschi (1998).

A noção de referência ainda persiste entre estudiosos cognitivistas clássicos. Essa perspectiva caracteriza-se por estabelecer um vínculo entre um referente no mundo e um significado linguístico desse referente, isto é, a proposta é de uma representação extensional de referentes do universo mental. Já do ponto de vista da referenciação, os estudiosos assumem a existência de uma realidade extramental, cuja apropriação tem implicações sociais e culturais, chamadas de versões públicas de mundo. Nessa perspectiva, a referenciação constitui-se em uma atividade discursiva, em que a realidade é mantida, construída, reconstruída e alterada por meio da forma como os sujeitos sociocognitivamente situados interagem com o mundo ( $\mathrm{KOCH}, 2002,2006)$.

Prosseguindo com Koch (2002), a referenciação, que, neste estudo, é entendida como elemento textual e linguístico discursivo-argumentativo presente na prática jornalística institucional, é concebida como uma prática interativa em que o sujeito opera sobre o material linguístico, realizando escolhas significativas para representar estados de coisas, com vistas 
à construção de sentido do seu querer-dizer. Assim, o conceito de referenciação pressupõe que a linguagem não se constitui em um sistema de etiquetas para referenciar os objetos, mas, sim, conforme asseveram Mondada e Dubois (2003), é uma atividade intersubjetiva, em que os sujeitos constroem, em suas práticas discursivas, versões públicas de mundo, o que implica reiterar uma visão de linguagem não referencial, afastando-se do sentido clássico da referência. Significa isso dizer que, na referência, as entidades designadas nas situações enunciativas referenciais são os objetos do mundo, enquanto que, no âmbito da referenciação, as entidades passam a ser objetos de discurso.

Nesse contexto, segundo afirma Koch (2002), os objetos do discurso não se confundem com a realidade extralinguística, mas reconstroem-se no processo de interação e, após serem introduzidos, são constantemente ativados, reativados, transformados, desativados e recategorizados. No processo, segundo Koch e Marcuschi (1998), os objetos de discurso não preexistem a atividade interativa a ele, mas são constituídos no interior do próprio discurso, o que aponta para a plasticidade das significações linguísticas.

Como a teoria da referenciação é o fundamento teórico do presente artigo, pontuam-se aqui alguns conceitos relacionados à referência, à remissão e à retomada, pois esses conceitos, não raras vezes, são concebidos de maneira equivalente. Para Koch (2002, p. 84), no entanto, os construtos citados são diferentes, sendo possível estabelecer a seguinte relação de subordinação hierárquica entre eles: (a) a retomada implica remissão e referenciação; (b) a remissão implica referenciação e não necessariamente retomada; e (c) a referenciação não implica remissão pontualizada nem retomada. Em seguida, Koch (2002) conceitua da seguinte forma os conceitos de referir, remeter e retomar: a) referir - atividade de designação realizável por meio da língua sem implicar uma relação especular língua-mundo; b) remeter - atividade indexical que se apoia na contextualização; e c) retomar - atividade de continuidade de um núcleo referencial, seja na relação de identidade entre elementos ou não.

Apresentadas as ponderações mais relevantes em relação ao processo de referenciação, aborda-se, na próxima seção, o conceito de referenciação, dando continuidade ao percurso teórico proposto. Na sequência, faz-se um paralelo entre a noção de anáfora como tradicionalmente concebida na literatura e a perspectiva sociocognitiva dos anafóricos, no quadro teórico da referenciação, foco de estudo do presente trabalho.

\section{ELEMENTOS ANAFóRICOS NA RETOMADA DE ENUNCIADOS}

Os processos decorrentes da textualização e da discursivização do mundo com a utilização da linguagem não ocorrem somente por meio da elaboração de informações, mas também pela reelaboração e pela reconstrução. Com essa afirmação, Mondada (2002) esclarece que a modificação de uma forma ou de um termo do texto implica na alteração do significado e do sentido do que está sendo comunicado, sendo precisamente nesse ponto que reside 
a necessidade de substituir a ideia de referência pela noção de referenciação, avaliando as performances discursivas e medindo o seu grau de correspondência com o mundo exterior.

Quanto a esse aspecto, Koch (2002) assevera que um mundo autônomo já discretizado em objetos, ou seja, a realidade física e social, existe independentemente de qualquer sujeito que a ele se refira, e que as representações linguísticas são instruções que devem se ajustar adequadamente a esse mundo. Nesse processo, ressalta que a noção de referenciação aciona três operações básicas: a) Ativação: pela qual um referente textual até então não mencionado é introduzido, passando a preencher um nódulo (endereço cognitivo, locação) na rede conceptual do modelo de mundo textual; a) Reativação: um nódulo já introduzido é novamente ativado na memória de curto prazo, por meio de uma forma referencial, de modo que o referente textual permanece saliente; e c) Desativação: quando ocorre a ativação de um novo nódulo, deslocando-se, assim, o referente que estava em foco anteriormente. Embora fora de foco, este continua a ter um endereço cognitivo (locação) no modelo textual.

À medida que a referenciação se configura como um sistema operacional de elementos designadores, segundo Koch (2002), todos os casos de progressão referencial são baseados em algum processo de referenciação, sendo que a determinação de uso desses referenciais se dá em detrimento dos demais elementos do contexto. Quanto às estratégias de progressão referencial e ao seu modo de constituição linguístico, Koch (2002) destaca: a) uso de pronomes ou elipses (pronome nulo); b) uso de expressões nominais definidas; e c) uso de expressões nominais indefinidas.

Em relação às formas gramaticais que exercem a função de pronome, Marcuschi (2008) comenta que são recursos com os quais os interlocutores constroem a cadeia dos elementos de que se fala no texto. Tais referentes são fundamentais para permitir ao alocutário perceber relações, metonímicas, metafóricas, hiponímicas, hipernímicas, de substituição, de associação e de inclusão, que contribuem para a compreensão textual.

No processo, a anáfora é um mecanismo que designa expressões textuais que retomam outros enunciados, conteúdos ou contextos e que produz progressão textual referencial. As anáforas diretas geralmente reportam referentes previamente introduzidos no texto, em uma relação de correferência entre elementos, ocasionando um processo de reativação dos referentes prévios. Já nas anáforas indiretas não existe congruência morfossintática entre a anáfora e seu antecedente, ou seja, o vínculo entre os termos não decorre de estabelecimento de relação referencial sintática direta entre elemento A e elemento B (MARCUSCHI, 2008).

Em função do exposto, a anáfora possui grande importância quando se fala em progressão textual, pois é ela quem estabelece, de forma direta ou não, a continuidade e a retomada dos objetos discursivos textuais. Assim, pensar em progressão textual remete a pensar no papel das anáforas, uma vez que os vínculos anafóricos são indispensáveis para a manutenção da temática textual, além de serem os elementos responsáveis por uma vasta gama de informação intratextual. Na sua atividade de remeter, o elemento anafórico pode reativar 
objetos de discurso introduzidos anteriormente ou ativar um novo elemento discursivo, cuja interpretação é dependente de dados introduzidos anteriormente (BRENT; ASSUNÇÃO, 2007).

Quanto à anáfora chamada de pronominal, é constituída por um pronome, sendo considerada uma anáfora direta $(\mathrm{AD})$, pelo fato de retomar um referente previamente introduzido no enunciado, estabelecendo uma relação correferencial entre o elemento anafórico e o seu antecedente. Segundo Marcuschi (2005, p. 55), "[...] a anáfora direta seria uma espécie de substituto do elemento por ela retomado". A discussão sobre a complexidade inserida nos processos de referenciação textual, contudo, gera polêmica mesmo hoje, porque nem sempre existe absoluta identidade referencial entre a anáfora e seu antecedente. Isto é, nem todas as anáforas são diretas e, por isso, nem todas as informações para a interpretação de um texto estão situadas no contexto imediato. Em vista disso, a ativação do conhecimento partilhado, ou a memória discursiva entre os interlocutores de que trata Apothéloz (2003), tornou-se um fator relevante a ser considerado nos processos anafóricos.

Sob vários aspectos, o uso de anafóricos parece extrapolar a mera função da retomada referencial estrita, assumindo um importante papel na construção de sentidos no texto, via processo de referenciação. O foco de análise do presente estudo segue esta senda, pois abrange a análise dos processos de referenciação inseridos como "adereços" textuais discursivo-argumentativos na prática jornalística institucional. Infere-se, desse ponto de vista, que o conceito de anáfora foi ressignificado, passando a ser concebido, também, como elemento responsável por recategorizações de referentes textuais.

Nessa perspectiva, Koch (2004, p. 69) salienta que o emprego de expressões nominais anafóricas geralmente atua na recategorização de objetos de discurso. Isto é, "[...] tais objetos vão ser reconstruídos de determinada forma, de acordo com o projeto de dizer do enunciador". Já o termo formas ou expressões nominais referenciais tem sido atribuído às formas linguísticas constituídas, basicamente, de um determinante (definido ou demonstrativo), seguido de nome. Essas formas nominais referenciais são responsáveis por dois grandes processos de construção do texto (e, consequentemente, do estabelecimento de sentidos no texto): o de retroação e o de prospecção $(\mathrm{KOCH}, 2002)$.

Na retomada não referencialmente estrita, as formas anafóricas operam na recategorização dos objetos de discurso, ou seja, na maneira como esses objetos serão reconstituídos, de forma a atender os propósitos comunicativos dos enunciadores. Koch (2006, p. 35) argumenta que, além da função de reconstrução dos objetos do discurso, as formas nominais trazem uma orientação argumentativa. Dessa forma, salienta que "uma das funções textual-interativas específicas é a de imprimir aos enunciados em que se inserem, bem como ao texto como um todo, orientações argumentativas conforme a proposta enunciativa do seu produtor". A orientação argumentativa a que se refere Koch (2006) será observada no corpus analisado no presente artigo, por meio das formas nominais mobilizadas para referenciar e recategorizar o objeto de discurso "Jornalismo institucional". 
Antes disso, de modo mais sistemático, pontua-se aqui a classificação das anáforas proposta por Koch e Elias (2006), que as subdividem em anáforas correferencias e não correferenciais. Para as autoras, nas anáforas correferenciais, ocorre a retomada de antecedentes textuais, podendo a retomada acontecer sem ou com recategorização do referente. As anáforas correferenciais sem recategorização podem surgir por repetição, quando o núcleo da forma nominal repete o antecedente que está sendo retomado, seja de forma parcial, seja na íntegra.

Quanto às anáforas não correferenciais, Koch e Elias (2006) explicam que se referem àquelas em que não há identidade estrita entre a anáfora e seu antecedente textual, sendo elas agrupadas da seguinte forma: a) Anáforas indiretas: quando um novo objeto de discurso é introduzido, sob modo de dado, em razão de algum tipo de relação com elementos presentes no cotexto ou no contexto sociocognitivo. No exemplo citado por Koch (2004, p. 254, grifo nosso), a expressão "pichações" ancora a interpretação de "as gangues": "Há alguns anos, as pichações que passaram a borrar casas, edifícios e monumentos de São Paulo [...] conforme a reportagem, as gangues reúnem-se semanalmente com hora e local marcados"; b) Nas anáforas rotuladoras (encapsulamento anafórico) surgem formas híbridas, referenciadoras e predicativas, que consistem em uma seleção particular e única entre uma infinidade de possibilidades lexicais para referenciar o objeto. No exemplo apresentado por Koch (2004, p. 256, grifo nosso), a expressão "a determinação" sumariza o conteúdo exposto anteriormente sobre a ação da "Vigilância Sanitária do Estado de São Paulo": "A Vigilância Sanitária do Estado de São Paulo determinou que todos os produtos transgênicos sejam recolhidos dos locais de venda. A determinação cumpre uma lei estadual de dezembro de 1999”; e c) Anáfora metadiscursiva consiste em um tipo de rotulação em que não se sumariza o conteúdo de um segmento textual precedente, mas focaliza-se a própria atividade enunciativa, qualificando esse segmento como determinado tipo de ação ou atividade metadiscursiva. No exemplo extraído de Koch (2004, p. 258, grifo nosso), a expressão "a simples sondagem” sumariza a atividade enunciativa exposta anteriormente sobre ação dos políticos em São Paulo: "Políticos procuraram o empresário Antônio Ermírio de Moraes sugerindo que ele saia candidato a prefeito de São Paulo. Mas a simples sondagem demonstra o estado emocional dos opositores da petista".

Até aqui foi exposto o quadro teórico em que se insere o presente estudo. Na sequência, são apresentados os procedimentos metodológicos empregados para a realização da pesquisa.

\section{Metodologia}

Para analisar o emprego da referenciação como mecanismo discursivo-argumentativo na prática jornalística institucional, bem como para verificar quais as incursões anafóricas contidas na composição hiperestrutural apresentada, propôs-se a análise de duas reportagens de divulgação acadêmica extraídas do Portal de notícias de uma IES, ambas publicadas em 2019. Com o intuito de não identificar a Instituição nem as reportagens, utilizaram-se os 
termos A e B para mencionar os excertos das referidas publicações. Para a análise textual, o parâmetro aplicado associa-se à teorização sobre referenciação, ancorado no dizer de Koch (2002, 2004), quando salienta que, na interação, o sujeito opera o material linguístico que tem à sua disposição, fazendo escolhas significativas para representar estados de coisas, com vistas à concretização do seu projeto de dizer.

A apresentação de uma configuração hiperestrutural foi o critério de segmentação do córpus, possibilitando o exame da dinâmica multiforme da correferenciação, considerada um aspecto crucial da construção dos sentidos. Para tanto, examinaram-se aspectos semânticos desses mecanismos ao longo do texto. Nessas publicações, para exemplificar a análise textual-discursiva da construção dos objetos de discurso no conjunto hiperestrutural, apresentam-se as publicações estudadas. Na sequência, para facilitar a leitura, constam as observações analíticas, acompanhadas de excertos da reportagem.

Figura 1: Excerto A - Primeira notícia selecionada

\section{INCLUIDASE CONECTADAS}

IDOSAS APRENDEM A USAR COMPUTADORES E SMARTPHONES EM AULA DE INCLUSÃO DIGITAL

Fonte: Portal da IES

1) Incluídas e conectadas: idosas aprendem a usar computadores e smartphones em aula de inclusão digital.

2) Todas as quintas-feiras, [...] elas se reúnem no Laboratório 1 [...] para aprender sobre o uso de tecnologias, como o computador e os smartphones. É o despertar de habilidades, uma nova experiência e segundo elas, uma forma de se sentirem incluídas na vida dos filhos, netos e mais integradas à comunidade.

3) A dona [...] afirma que já aprendeu várias funções do computador e também do celular, o que mantém a mente dela sempre ativa. "É muito bom para exercitar o cérebro e eu geralmente guardo tudo de cabeça.

4) Sempre aprendendo. "Se eu puder te dar um conselho, será esse: nunca pare de estudar", estas são as palavras da aposentada [...], que conta que embora nunca tenha cursado uma graduação. "Eu estou todo o tempo buscando conhecimento e aqui eu já aprendi tantas coisas. Está sendo ótimo, porque o que eu sabia, era só “uma aguinha doce”, ressalta.

5) De acordo com a acadêmica [...] ensinar também tem sido uma descoberta. "Eu tenho aprendido muito a nível acadêmico e pessoal", enfatiza. 
Analiticamente, em um primeiro momento, nas expressões "Incluídas" e "conectadas" (1), os referentes textuais ativados associam-se a dois pontos de vista: o primeiro é o de que a INCLUSÃO pressupõe o não dito relacionado à exclusão, ou seja, quem precisa ser incluído em alguma situação é porque está fora dessa situação ou condição; e CONECTADAS referencia o mundo interligado pela internet, mas que pertence à nova geração (plugada), pois, se somente agora essas pessoas estão conectadas, é porque antes estavam fora do mundo virtual, quase que exclusivo dos mais jovens. Ao predicar, na sequência, "idosas" e "inclusão digital", a referenciação remete à discriminação existente pelo fato de serem mulheres e de mais idade (idosas), assim como ao aspecto digital já mencionado, ou seja, a mulher mais velha era e é, em geral, uma dona de casa. Ela se incumbe de cuidar dos filhos e, em consequência, a mulher idosa é a avó, que costuma ser iletrada do ponto de vista digital e que continua sendo apenas a cumpridora de afazeres domésticos.

No sentido literal, a inclusão digital consiste em disponibilizar para todos os cidadãos, de modo igualitário, a oportunidade de ter acesso às tecnologias de informação e comunicação (TIC's). Assim, o título da matéria já exige do leitor inferências e conhecimentos de mundo para que possa compreender o(s) seu(s) sentido(s), pois vários deles podem ser inferidos a partir de uma construção discursiva que, em uma interpretação isolada, desconectada do mundo atual, pode remeter a interpretações outras. Parece, pois, que essa deferência com as idosas dialoga com a afirmação de Marcuschi (2010), quando explica que só há sentido em falar de leitura quando se considera o conceito de compreensão, e não "copiação" de informações soltas no texto, classificando esse processo como necessário ao leitor, para que associe informações, levante hipóteses e produza inferências. Da mesma forma, só há sentido em falar de inclusão digital de idosas se a pessoa - a idosa - conseguir entender a mensagem subliminar que, de fato, a vê como alguém dispensável a quem é oferecida uma possibilidade única de integrar o mundo atual, como se, sem isso, ela fosse dispensável por ser ultrapassada. E os homens velhos, por que não foram chamados a participar?

Em seguida, no item (2), instauram-se novos referentes, com os termos "aprender sobre o uso de tecnologias", que se relaciona ao enunciado anterior, o qual explicita que esse público composto por pessoas de mais idade (idosas) tem dificuldades de lidar com tecnologia; em "despertar de habilidades" o termo remete a fazer nascer ou trazer à existência habilidades do ponto de vista da evolução tecnológica; enquanto os referentes "incluídas na vida dos filhos, netos e mais integradas à comunidade" reiteram o discurso inicial relacionado à EXCLUSÃO, no sentido de sugerir que, por estarem conectadas, elas (idosas), consequentemente, terão mais importância, marcando presença na família e na sociedade, algo que sem o uso frequente da tecnologia não é possível ou viável para aquelas que não estudaram, isto é, não fizeram um curso de graduação, segundo se depreende do depoimento da entrevistada. Entretanto, a função da retomada no contexto em que ocorreu é a de dar uma melhor definição ao referente instaurado anteriormente acerca do tema em voga (inclusão digital), com a ideia de criar um 
processo de construção de objetos de discurso que, ainda que de forma implícita, consiste na divulgação das ações extensionistas da Instituição junto à comunidade.

No decorrer do item (2), a referência anafórica "elas" atua como forma gramatical que exerce a função de retomar a expressão "idosas", no que Marcuschi (2008) revela ser um recurso bastante utilizado, com o qual interlocutores constroem a cadeia dos elementos de que se fala no texto. Por meio desse mecanismo, os falantes mantêm o controle daquilo que já foi enunciado, tendo a anáfora a função de repetir a identificação do referente já reconhecido a partir de outra expressão num dado discurso. As anáforas diretas, como foi o caso aqui utilizado (ELAS), geralmente reportam referentes previamente introduzidos no texto em uma relação de correferência entre os elementos e ocasionam um processo de reativação dos referentes prévios.

No tópico (3), os referentes "mente sempre ativa" e "exercitar o cérebro" identificam duas metáforas dualistas do corpo, à la Descartes, tendo, como fio condutor, o papel da metáfora na construção de objetos de discurso, ou seja, no processo de referenciação (MONDADA; DUBOIS, 2003). A construção metafórica remete à importância de estudar e adquirir novos conhecimentos. Aqui, vale ressaltar o dizer de Nunes (2009, p. 42) sobre o papel das metáforas na construção discursiva, ao afirmar que se trata de uma racionalidade inventiva, ou seja, de uma forma imaginária da racionalidade imprescindível à nossa conceituação do mundo. Sendo assim, "a metáfora passa a ser entendida não somente como padrão de pensamento e organização da linguagem, mas como estruturadora da própria atividade cognitiva, proporcionando ignição aos atos do corpo".

Na sequência, no tópico (4), os referentes "Sempre aprendendo", "nunca pare de estudar", "cursado uma graduação", "todo o tempo buscando conhecimento", enriquecidos com a inserção de vozes/narrativas de experiências, remetem a referenciações dirigidas ao ensino, à frequência aos bancos acadêmicos, razão pela qual a instituição analisada existe. Tais unidades lexicais expõem uma propaganda velada/implícita em meio a um texto jornalístico de cunho informativo, no sentido de destacar a importância do aprendizado e da abrangência do conhecimento obtido na Universidade por meio dos cursos oferecidos. Esse processo, para Koch e Elias (2006, p. 21), revela que "[...] a leitura e a produção de sentidos são atividades orientadas por nossa bagagem sociocognitiva: conhecimentos da língua e das coisas do mundo”. Já a expressão "uma aguinha doce" (4) aciona uma metáfora morta incorporada pela língua, ou seja, que perdeu seu caráter inovador, original e transformou-se numa metáfora comum, morta, que não mais causa estranheza (SEARLE, 1995). No texto, a expressão revela que a idosa sabia muito pouca coisa em relação ao tema tecnologia antes de participar do curso.

Já "ensinar", "descoberta" e "nivel acadêmico" presentes no exemplo (5) reforçam a tese relacionada à relevância de se buscar aprendizado, enaltecendo a importância do ensino/ aprendizagem. Na ótica de Kleiman (1992), observa-se que tais expressões fazem com que sejam acionados conhecimentos prévios - linguísticos, textuais, enciclopédicos, intertextuais, 
contextuais - e, em vista de sua presença, sejam feitas determinadas associações e produzidas inferências relacionadas aos implícitos e conhecimentos de mundo mobilizados. Nesse caso, o conhecimento intertextual é que colabora para que sejam identificadas as referências, explícitas ou implícitas, a outros textos e contextos.

Assim, ler o texto compreendendo a inter-relação entre os referentes textuais ativados demanda a produção de inferências e a descoberta de pistas que orientem o leitor em relação ao que está sendo enunciado. Tais indícios são oferecidos na notícia analisada, uma vez que, inicialmente, é explicitado o tema a ser enfocado, já que as expressões nominais utilizadas fazem parte de um mesmo campo discursivo, o campo da inclusão digital associado à necessidade de atualização e aprendizado.

Figura 2: Excerto B - Segunda notícia selecionada

\section{6/09: DIA NACIONAL DOS SURDOS UNIVRSIDADE \\ CELEBRA A DATA COM OFICINAS GRATUITAS DE LIBRAS}

Fonte: Portal da IES

1) Dia Nacional dos Surdos: universidade [...] celebra a data com oficinas gratuitas de libras.

2) Muitos direitos já foram conquistados pelos surdos no Brasil. Entre eles a oficialização das Libras como a segunda língua nacional, a obrigatoriedade do ensino de Libras na formação de professor, a obrigação do ensino bilíngue para crianças com deficiência auditiva e a obrigatoriedade da presença de um intérprete de Libras nos órgãos públicos.

3) Esses alunos contam com o acompanhamento de intérpretes desde o Vestibular ou caso optem por outra forma de ingresso, auxiliando no processo de matrícula. Após o ingresso na Universidade, eles têm o atendimento das intérpretes em sala de aula [...].

4) Entendo que o nosso diferencial é a acolhida, sempre mencionada pelos alunos que passam por aqui, é nossa marca", analisa.

5) Nesse ano o departamento de Marketing da Instituição promoveu uma campanha, com objetivo de dar visibilidade para essa causa e para a importância da inclusão.

6) Percebemos essa união e a igualdade que é estabelecida com os surdos aqui, avalia a ex-aluna do curso de Design, [...]. A presença desses colaboradores aqui não é apenas uma preocupação com o cumprimento de uma legislação, vai além disso. É compartilhar o mundo com a sua diversidade e respeitá-los", destaca [...].

Ao analisar os campos semânticos grifados, percebe-se que as estratégias de retomada do referente para a construção do objeto de discurso, no item 1, "Dia Nacional dos Surdos", foram partilhadas e negociadas pelos indivíduos que interagem em uma data comemorada anualmente, em 26 de setembro, data que relembra a história e a luta dessa comunidade. No percurso de análise, observa-se que o termo "celebra" alude ao campo da exaltação, no sentido 
de comemorar os direitos e refletir sobre a inclusão das pessoas com deficiência auditiva na sociedade, com a inserção subsequente do referente "oficinas gratuitas de libras", no sentido de demonstrar o relevante papel social desenvolvido pela instituição, ao oferecer oficinas gratuitas para a comunidade, reforçando sua missão de contribuir para o desenvolvimento da região em que está inserida. No dizer de Anscombre e Ducrot (1988), tratando-se da argumentação, a utilização de um enunciado tem uma finalidade ao menos tão essencial quanto a de informar sobre a realização de suas condições de verdade, que é a de orientar o destinatário para certas conclusões e não para outras.

No tópico 2, os excertos "segunda língua nacional", "obrigatoriedade do ensino de Libras", "ensino bilíngue", "deficiência auditiva" e "obrigatoriedade da presença de um intérprete de Libras nos órgãos públicos" ativam referentes para a direção do que está implícito, no que tange à formação na área. O referente "obrigatoriedade", por exemplo, pressupõe a existência de uma norma legal até então não existente, quanto à questão do ensino de Libras e, também, do apoio dado aos estudantes surdos que frequentam as salas de aula, no caso, a presença de um intérprete nas aulas e nos órgãos públicos. Essas expressões se constituem em mecanismos para a construção de um discurso no sentido de incentivar a formação na área de Libras, uma vez que, a partir da "obrigatoriedade" desse tipo de conhecimento linguístico, novos campos profissionais começaram a ser abertos. Nessa perspectiva é que Koch e Elias (2006, p. 13) ressaltam ocorrer a ativação dos conhecimentos dos leitores em interação com o autor e o texto, começando com antecipações e hipóteses, sendo a leitura, portanto, uma atividade estratégica de levantamento de hipóteses, conforme objetivos específicos.

Tais constatações são acrescidas, no item 3, por meio dos referentes "forma de ingresso", "processo de matrícula", "após o ingresso", "atendimento das intérpretes" e "atividades extraclasse", que remetem à produção de sentido centrado no chamamento de estudantes para a instituição, já que o seu público-alvo é justamente este. Para Koch e Elias (2006), esses referentes que ativam o conhecimento enciclopédico são também chamados de conhecimento de mundo, ou seja, referem-se a tudo o que é assimilado no decorrer da nossa vida. Em decorrência disso, ao ler um texto, sempre retomamos, de certa forma, na nossa memória, o que já lemos e conhecemos para fazer inferências e compreender o texto que está sendo lido. A referenciação aqui se constitui no que Borges (2019, p. 36) considera como uma manobra do enunciador para validar sua proposta. Em decorrência disso, "se a forma de operar com os objetos de discurso implica em uma atividade de seleção visando à produção de sentidos que denotam um ponto de vista, então é possível estabelecermos uma relação entre referenciação e argumentação”.

No item 4, as expressões "nosso diferencial", "acolhida" e "nossa marca" traduzem um discurso institucional dirigido à política de acessibilidade proposta pela instituição de ensino. As inserções na sequência, a partir dos referentes "campanha", "visibilidade", "causa" e "inclusão" (5), buscam reconstruir a coerência do texto para que o leitor consiga recuperar o objeto de discurso no relato em análise, relacionando-o à comunidade surda. Nessa concepção mais 
pontual, a anáfora "causa" aparece prioritariamente ligada à coesão textual, sendo um elemento estritamente responsável pelas retomadas de itens já textualizados, reforçados pelos termos "união", "igualdade", "cumprimento de uma legislação", "compartilhar o mundo" e "diversidade" (6). Por meio do mecanismo anafórico, é possível retomar um referente previamente introduzido no enunciado, estabelecendo uma relação correferencial entre elemento anafórico e antecedente, que, para Marcuschi (2008), representa uma espécie de substituto do elemento retomado para orientar a leitura.

\section{Considerações FinaIS}

Este estudo permitiu analisar a forma como os processos de referenciação são empregados enquanto elementos estratégicos textuais e linguístico-discursivos na prática jornalística institucional em uma IES do RS, atuando como recursos mobilizadores na atividade de divulgação para consolidar uma imagem positiva, propagar ações diversas e buscar, por meio dessas divulgações, atrair novos estudantes. A análise possibilitou detectar a riqueza de possiblidades de interpretação de um mesmo texto, assim como também foi possível observar a importância que os recursos linguísticos e textuais desempenham, nesse caso a referenciação, na composição hiperestrutural e na orientação discursiva dos enunciados.

Comprovou-se, por outro lado, que os recursos textuais considerados se configuram em mecanismos de recategorização do objeto de discurso, contribuindo para a instauração dos propósitos discursivos do enunciador. Em síntese, evidenciou-se que, no processo de referenciação, as formas textuais e linguísticas foram construídas a partir do compartilhamento cognitivo de diversas versões sobre o objeto de discurso específico, nesse caso, "o jornalismo institucional". Foi possível, ademais, demonstrar que cada expressão, ao ser inserida no discurso, pode modificar o sentido textual, em sua totalidade, evidenciando-se, assim, o quanto a escolha das palavras é relevante para se atingir o efeito desejado.

Concluiu-se, por fim, que a forma de nomear um objeto discursivo é constituída por elementos preestabelecidos na memória discursiva dos leitores e dos redatores; por isso, esses recursos foram frequentemente mobilizados nos textos jornalísticos analisados. Ressalta-se, ainda, que o uso da referenciação no jornalismo institucional contribui para a construção da argumentatividade, porque marca a posição do enunciador diante do objeto do discurso em foco, revelando um movimento de referenciar de modo a dar uma visão positiva da Instituição.

De outra parte, ressalva-se que, nos processos de referenciação, usualmente são fornecidas pistas para orientar o leitor quanto ao conteúdo disponibilizado discursivamente, porém a leitura a ser feita demanda do leitor muita atenção, além da produção de inúmeras inferências e da captação de alusões e implícitos por vezes não apreendidos numa primeira leitura, mais desavisada. 


\section{REFERÊNCIAS}

ANSCOMBRE, Jean Claude; DUCROT, Oswald. L'argumentation dans la langue. Liège/ Bruxelas: Pierre Mardaga, 1988.

APOTHÉLOZ, Denis. Papel e funcionamento da anáfora na dinâmica textual. In: CAVALCANTE, Mônica Magalhães; RODRIGUES, Bernadete Biasi (org.). Referenciação. São Paulo: Contexto, 2003. p. 53-84.

BAKHTIN, Mikhail. Os gêneros do discurso. In: BAKHTIN, Mikhail. Estética da criação verbal. São Paulo: Martins Fontes, 2003.

BORGES, Euclides Hélio de Fátima Campos. Referenciação e ideologia: a construção de sentidos no gênero reportagem. Londrina: Eduel, 2019. 188 p.

BRENT, Rocha; ASSUNÇÃO, Antônio Luiz. Discurso, referenciação e sentido: a crise política na mídia. In: CONGRESSO BRASILEIRO DE CIÊNCIAS DA COMUNICAÇÃO DA REGIÃO SUDESTE, 12., 2007, Juiz de Fora. Anais [...]. Juiz de Fora, 2007. Disponível em: http://www. intercom.org.br/papers/regionais/sudeste2007/resumos/R0286-1.pdf. Acesso em: 15 nov. 2019.

CAVALCANTE, Mônica; SANTOS, Leonor. Referenciação e marcas de conhecimento partilhado. Linguagem em (Dis)curso, Tubarão, SC, v. 12, n. 3, p. 657-681, set./dez. 2012. Disponível em: http://www.scielo.br/pdf/ld/v12n3/ao2v12n3.pdf. Acesso em: 10 nov. 2019.

KOCH, Ingedore G. V. Desvendando os segredos do texto. 4. ed. São Paulo: Cortez, 2002.

KOCH, Ingedore G. V. Léxico e progressão referencial. In: RIO-TORTO, G. M.; SILVA, F.; FIGUEIREDO, O. M. (Org.). Estudos em homenagem ao Professor Doutor Mário Vilela. Porto: Faculdade de Letras da Universidade do Porto, 2006.

KOCH, Ingedore Vilaça. Introdução à linguística textual. São Paulo: Martins Fontes, 2004.

KOCH, Ingedore Vilaça; ELIAS, Vanda Maria. Ler e compreender: os sentidos do texto. São Paulo: Contexto, 2006.

KOCH, Ingedore Vilaça; MARCUSCHI, Luiz Antônio. Processos de Referenciação na Produção Discursiva. DELTA, v. 14, n. Especial, 1998.

KLEIMAN, Ângela. Texto e leitor: aspectos cognitivos da leitura. 2. ed. Campinas: Pontes: Unicamp, 1992.

MARCUSCHI, Luiz Antônio. Anáfora Indireta: o barco textual e suas âncoras. In: KOCH, I. V., MORATO, E. M.; BENTES, A. C. (Org.). Referenciação e discurso. São Paulo: Contexto, 2005.

MARCUSCHI, Luiz Antônio. Produção textual, análise de gêneros e compreensão. São Paulo: Parábola, 2008.

MARCUSCHI, Luiz Antônio. Da fala para a escrita: atividade de retextualização. 10. ed. São Paulo: Cortez, 2010. 
MONDADA, Lorenza. Construction des objets de discours et catégorisation: une approche des processus de référenciation. Tradução de Mônica Magalhães Cavalcante. Revista de Letras, n. 24, v. 1/2, jan./dez. 2002. Disponível em: http://www.revistadeletras.ufc.br/rl24Art21.pdf. Acesso em: 12 nov. 2019.

MONDADA, Lorenza; DUBOIS, Daniele. Construção dos objetos de discurso e categorização: uma abordagem dos processos de referenciação. In: CAVALCANTE, M. M.; RODRIGUES, B. B. (Org.). Referenciação. São Paulo: Contexto, 2003.

NUNES, Sandra Meyer. As metáforas do corpo em cena. Florianópolis: Annablume, 2009.

SANTOS, Leonor Werneck; CUBA RICHE, Rosa; TEIXEIRA, Cláudia. Análise e produção de textos. São Paulo: Contexto, 2012.

SEARLE, John. Expressão e significado - estudo da teoria dos atos de fala. São Paulo: Martins Fontes, 1995.

Recebido para publicação em: 30 abr. 2020. Aceito para publicação em: 12 ago. 2020. 